\title{
Complimentary address from the President of the American Phytopathological Society
}

\author{
Rick Bennett ${ }^{1}$
}

Published online: 9 October 2015

(C) The Phytopathological Society of Japan and Springer Japan 2015

Dear members and colleagues of the Phytopathological Society of Japan;

I am honored to be invited to the 100th Anniversary Ceremony of the Phytopathological Society of Japan (PSJ). As President of the American Phytopathological Society (APS), it is my privilege to extend greetings from APS and a sincere offer of partnership and collaboration as you celebrate the 100th anniversary of the Phytopathological Society of Japan.

During my commemorative lecture, I will discuss the many global challenges in plant pathology both APS and PSJ face in this new era of international agriculture. I will offer my insight into the complexity of global issues and my views on the future of our discipline. I will also present

an overview of the interrelationships among and between organisms in the plant biome and the importance of microbial collections for research.

As the PSJ enters a new century as a premier society of plant pathology, APS welcomes the opportunity to develop strategic partnerships with PSJ with mutually agreeable goals. It is my wish that our partnership will promote the highest quality research and professional standards in plant pathology, that we will together disseminate useful plant health information and knowledge, and foster professional growth and development among our society members. I look forward to attending the 100th anniversary celebration of PSJ. Thank you and best wishes from APS.

This article is an abstract of the complimentary address given at the 100th Anniversary Ceremony of the Phytopathological Society of Japan, which was held on Saturday, March 28, 2015, at Academy Hall, Academy Common Building of Meiji University, Tokyo, Japan.

Rick Bennett was former President of the American Phytopathological Society (until August 2015).

Rick Bennett

rick.bennett@uky.edu

1 Kentucky Agricultural Experiment Station, University of Kentucky, S129 Agricultural Science Building North, Lexington, KY 40546-0091, USA 